\title{
Apuntes para una reflexión: nuevas tendencias de la literatura para niños y jóvenes
}

María Pérez Yglesias

Escuela de Ciencias de la Comunicación Colectiva Universidad de Costa Rica

\section{Introducción}

\subsection{Los espacios y los límites}

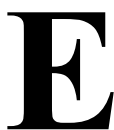
1 título (el nombre) de un artículo, de un discurso, de una película, de una pintura... es siempre, de alguna manera, la marca de un espacio y un límite. Informa, sugiere, invoca, persuade sobre su consumo, condiciona una lectura (escucha, visión...) pero, sobre todo, crea en el perceptor -también participante- unas expectativas marcadas por su propio saber sobre la temática, su perspectiva filosófica, su posición ideológico-social.

¿Cuáles son los espacios y los límites que marca, entonces, el nombre de la conversación de hoy?

Los límites son la "novedad", el carácter literario de las prácticas significantes que se deben referir y la edad de los lectores virtuales: niños y jóvenes.
El espacio resulta bastante abierto si se toma en cuenta la discusión en torno a las concepciones de literatura y si se percibe que las llamadas "nuevas tendencias" no pueden ser concebidas fuera del proceso histórico-social que las precede y sin el contexto de las otras prácticas significantes que dialogan con ellas, las cuestionan, justifican o niegan.

Las reflexiones de hoy son -contrario a las prácticas significantes de las que se hablapara adultos, para escritores de literatura, para educadores, para editores de textos, para críticos literarios, para encargados de instituciones culturales... todos - supuestamente- con un interés común: la literatura para niños y adolescentes.

Y en este proceso de producción -que en este momento (ahora) entra en la cadena comunicativa- quien asume el trabajo se pregunta: ¿cuál es el "horizonte de espera" de ustedes, y cómo, de cierta forma y talvez sin concretarlo en la conciencia, ustedes condicionan este discurso? 


\subsection{Una vieja problemática en un nuevo discurso}

Pensar sobre las "nuevas" tendencias lleva, irremediablemente, a reflexionar sobre viejos y controversiales problemas:

- ¿qué es literatura?,

- ¿existe o no una especificidad para la literatura dirigida a niños?,

- ¿se dan diferencias significativas con la literatura para jóvenes?,

- ¿los nombres "literatura para niños" y "literatura infantil" significan diferencias de orden epistemológico e ideológico?,

- ila controversia entre las distintas maneras de enfocar la etapa infantil y adolescente condiciona las prácticas literarias destinadas a ellas?

- ¿la problemática actual, cotidiana y trascendente, con sus adelantos y sus grandes errores, con sus actos solidarios, sus miedos, sus locuras y negatividades son temática para la infancia?,

- ¿la literatura para niños debe ser, por el contrario, el espacio del juego, de la fantasía y la magia, de las brujas y los duendes, de los sueños y la imaginación, del "había una vez, en un lugar muy lejano y exótico"?

- ila literatura para los infantes y los muchachos puede abstraerse realmente de la memoria histórica, de las condiciones reales e imaginarias de existencia de los hombres comunes, de las informaciones políticas y económicas, de las discusiones ideológicas, de la realidad de las instituciones en que participa cotidianamente?
El desafío que ahora se presenta abarca, al menos, dos reflexiones fundamentales:

- la primera, de orden más teórico, que se aproxima a la concepción de la literatura para niños y jóvenes;

- la segunda se refiere, específicamente, a las llamadas "nuevas tendencias".

\section{Hacia una concepción de la literatura}

Las discusiones planteadas por la filosofía, la ideología, la axiología y las distintas ciencias sociales le atañen a la literatura. Los planteamientos de los sicólogos, los maestros, los críticos literarios, los historiadores, los semióticos y los escritores mismos condicionan el trabajo con la lengua, el trabajo con los textos del pasado y el presente, para construir un nuevo texto literario (estético), no importa el lector virtual (más o menos específico) a quien se dirija.

Enfrentar teórica y críticamente la literatura -como práctica social- exige una actitud:

- transdisciplinaria (interdisciplinaria),

- translingüística (la conciencia de que está hecha por medio de la lengua pero que es irreductible a sus categorías),

- transimbólica (un punto de partida que no considera el sentido preexistente, ni la verdad objetiva) y

- transcomunicativa (donde se atraviese el escenario de lo representativo, lo comunicativo, lo intercambiable para introducirse en el de la producción, el trabajo, el proceso). 
Si se parte de esta posición, resulta fundamental hacer algunas observaciones generales sobre la literatura:

- es una práctica (trabajo) significante (produce sentido) específica (carácter estético, de acuerdo con un espacio, un tiempo, un grupo social, una memoria histórica);

- su búsqueda no es ontológica (los problemas del ser y la existencia), ni ética (la verdad y la falsedad) aunque plantee problemáticas existenciales y de orden moral;

- trabaja con la lengua (y sus reglas de combinación) pero la transforma $\mathrm{y}$ subvierte en la palabra (el habla);

- aunque en la cadena de comunicación se presente como un producto, listo para el consumo (libro, revista, periódico, afiche...) es siempre una productividad, un diálogo abierto, un hacerse continuo e infinito, unas posibilidades combinatorias múltiples y complejas;

- como texto (y el literario no es la excepción y el literario para niños tampoco) es una intertextualidad: un diálogo de textos múltiples anteriores y sincrónicos que lo componen y una relación continua con el contexto o texto general de la historia y de la cultura.

Ese texto general de la historia y de la cultura forma parte del particular -en este caso la práctica significante literaria- y este texto específico, en relaciones plurales (en volumen, no en la línea causa-efecto) con otras prácticas sociales (significantes y materiales) configuran ese texto general:

- como productividad y como intertextualidad todo texto es social, es histórico, es cultural y, por tanto, de alguna manera es colectivo.

- Si se trabaja en la cadena de la comunicación:

- El escritor trabaja con la lengua y con discursos múltiples. Lee, redistribuye, combina, privilegia, omite, juega, escribe...

- Yel lector-en este caso marcado por la edad- es un perceptor y a la vez un escritor de su propia versión de lo leído. Se inserta en el texto como parte de la historia y la cultura a la que pertenece y participa directamente en el proceso de esa productividad siempre abierta. Él también privilegia, sugiere, juega, rompe o consolida la significación.

Así, aun dentro del esquema comunicativo (productor-texto-perceptor), esta noción de literatura privilegia la productividad, el proceso, sobre la circulación.

La literatura -como todas las prácticas sociales, prácticas significantes- forma parte de la semiosis social que se construye como una programación y reproducción social y, a la vez, como un lugar de producción y transformación del sentido, como un espacio donde se debaten las ideologías y se afirman y discuten los modos de producción.

La concepción de literatura como una práctica significante particular -donde la dirigida a los niños y jóvenes solo representa otra particularidad- abre y orienta las respuestas a los problemas apuntados en las preguntas anteriores. 


\section{Nuevas "tendencias" de la literatura para niños y jóvenes}

Las posibilidades de discusión son tan amplias que obligan de nuevo a una escogencia, casi a una enumeración que depende no sólo de la pertinencia o importancia, sino de los intereses personales e incluso, de las expectativas que ustedes tengan sobre la problemática.

¿Qué se entiende por "tendencias" y dónde -a partir de cuándo- se ubica la "novedad"?

La noción de "tendencia" es bastante amplia y ambigua, remite a posibilidades múltiples y permite asumirla desde diferentes puntos de vista:

- puede significar "movimiento literario", "género", "estilo", "temática", "perspectiva ideológica";

- puede ubicarse en relación con los cambios más evidentes de la sociedad y la cultura dominantes en el país;

- puede referirse a los aportes que distintas disciplinas y técnicas le dan a la literatura infantil;

- puede pensarse en relación con el escritor, con el proceso de legitimación, con las instancias o instituciones de apoyo, con las posibilidades de divulgación...

La ubicación temporal también resulta abierta y depende simplemente de una decisión arbitraria (pensar el último quinquenio o el último cuarto de siglo...) o de lo que interese discutir como "tendencia" y las marcas de transformación que se ubiquen en los textos mismos (literatura para niños y jóvenes) o en el contexto (local, costarricense o internacional...).
Las observaciones anteriores explican y condicionan que esta parte del trabajo (la de las "nuevas tendencias") se convierta en una serie de breves planteamientos que abran el espacio de la discusión reflexiva y provoquen la necesidad de "nuevas" investigaciones en cada una de las áreas. Más que un desarrollo, se trata de un "mosaico" de ideas fragmentario, sugerente, incompleto.

\subsection{En torno al proceso de producción}

- En una primera etapa de la literatura infantil en Costa Rica, existe una clara predominancia de autores que tienen el oficio de "maestros" y los textos de carácter didáctico literario ocupan un espacio importante. Luego, el espectro de oficios de los escritores de literatura para niños se amplía: piénsese, por ejemplo, en Rodolfo Dada, Femando Durán, Mabel Morvillo, Alfonso Chase... La contribución de los educadores, sin embargo, sigue siendo muy significativa: Floria Jiménez, Delfina Collado, para solo citar unos nombres.

- La investigación de la realidad circundante, del pasado, se convierte en una preocupación de los escritores y esto los lleva, algunas veces, a una relación interdisciplinaria. Los aportes de lingüistas y antropólogos para quienes trabajan el pasado indígena (por ejemplo, Floria Jiménez o Alfonso Chase) son fundamentales; los de los biólogos u otros especialistas en medio ambiente les sirven de base a algunos textos que privilegian el problema ecológico (algunos de los publicados en la Serie Mapachín de la Universidad Estatal 
a Distancia); los de los historiadores dan la base para recrear personajes o acciones del pasado.

\subsection{En torno a los textos propiamente dichos}

En la literatura, ese sentido haciéndose en el diálogo y confrontación de sentidos múltiples, en la negación y la afirmación, en las huellas históricas y en la proyección de futuro no se construye solamente como un significado explícito, en una temática particular. Se construye en el material significante mismo (en este caso la lengua articulada), en la lógica de las relaciones, en la combinación de códigos, en la distribución del espacio.

\subsubsection{Las temáticas}

Por "nuevas tendencias" de la literatura para niños y jóvenes se entiende, muchas veces, las "nuevas temáticas" o las "nuevas problemáticas" sobre las que se escribe.

Las temáticas pueden variar infinitamente sin que la lógica que las sostiene (programaciones sociales) se modifique estructuralmente y toque el modo de producción (material o significante). Sin embargo, un cambio temático, de focos de interés también resulta significativo y puede llevar a percibir una transformación en otros niveles.

Antes de referimos brevemente a algunos de los temas privilegiados por los escritores costarricenses (calificados como escritores para niños y jóvenes) en la última década, es importante recordar que:

- la literatura actual forma parte de un proceso histórico que no se puede desconocer, por eso, más que un cambio de temática o de tipos de personajes, lo que se percibe es una modificación en la perspectiva;

- la literatura como práctica social, histórica, cultural no escapa -ni siquiera cuando se trata de literaturas no realistas- del contexto en que se produce y con el que dialoga. Las preocupaciones actuales en otras áreas marcan, en muchas ocasiones, las tendencias temáticas;

- cuando se hace referencia a unas preferencias temáticas hay que tomar en cuenta que, a menudo, se perciben mezcladas en un solo texto.

En la actualidad se perciben como tendencias temáticas predominantes:

- la valoración de lo propio frente a lo ajeno, lo conocido frente a lo exótico siguiendo la línea más tradicional de la literatura costarricense.

La primera literatura de la que se habla en el país como propia o accesible a niños y jóvenes es la que parte de la tradición popular. Carmen Lyra recoge los famosos Cuentos de mi tía Panchita en la Meseta Central (centro de la cultura hegemónica costarricense) y María Leal de Noguera trabaja los Cuentos Viejos, de Guanacaste. Y la que se refiere a lo nacional con un sentido básicamente personal: el amor a las cosas cotidianas, a la herencia del pasado, a los recuerdos de infancia, a la naturaleza percibida; Carlos Luis Sáenz representa muy bien esta nostalgia y cercanía. Delfina Collado, Mabel Morvillo, Manuel Aguilar... marcan en el presente esa tendencia. 
En la actualidad los escritores costarricenses siguen refiriéndose a tópicos semejantes pero algunos varían el enfoque. La cultura de la Meseta Central se continúa valorizando pero se abre un espacio fundamental a las culturas de minorías y sus respectivas visiones de mundo

El negro, pero sobre todo el indio, dejan sus huellas como personajes -individuales o colectivos-en la literatura costarricense: El delfin de Corubici de Anastasio Alfaro, Yorusti de Carlos Luis Sáenz, el negrito Cocorí de Gutiérrez Mangel. La mayor parte de las veces se trata de un "color de la piel" más que de un sentido de pertenencia, de una perspectiva cultural que condiciona una manera de ser y de vivir en relación con otras.

Una nueva tendencia en la literatura actual, ya iniciada claramente por Adela Ferreto en La creación de la tierra y otras historias del buen Sibú y de los Bribrís, es continuada por Alfonso Chase, Floria Jiménez Rodolfo Dada y Quince Duncan. Se trata para ellos de trabajar - directa o indirectamente- sobre la tradición oral que se trasmite de generación en generación: la de los bribrís o cabécares -recogida originalmente por antropólogos y lingüistas- en un caso, y el de la tradición de los negros limonenses, en otro.

- La naturaleza y los adelantos técnicocientíficos: Un segundo ejemplo que resulta evidente es el del canto a la naturaleza: aún muchos de los escritores de hoy hablan de la flora y la fauna del país, de las bellezas naturales, se sitúan en lo rural y siembran los campos.
Sin embargo, en este momento, lo que se privilegia es el problema ecológico: la protección necesaria ante una destrucción inminente. Adela Ferreto con textos como El mundo de las palabras y otros cuentos se percibe también como pionera en este campo.

La Universidad Estatal a Distancia y su editorial (EUNED) han dado un aporte significativo mediante sus concursos y publicaciones. La serie Mapachín -dedicada sobre todo a los adultos del mañana- está dedicada a esta problemática.

Un tercer ejemplo es el de la introducción de lo moderno, de las "nuevas tendencias", "los avances científicos", "la sociedad de desecho y de consumo". Como muestra se podrían señalar algunos textos de Floria Pinto. Pero, en general, el mundo de la naturaleza sigue conservando su hegemonía sobre los avances de la civilización. Adela Ferreto abre una brecha importante en este campo.

- La introducción de la variable política. Otra temática que se perfila es la político-social casi ausente en la tradición de la literatura para niños y jóvenes. Los ocho pericos de Rodolfo Dada sirve de ejemplo. El huevo del ave Rock y otros cuentos de Adela Ferreto tocan el tema político. En este caso, el ave Rock es el avión que deja caer su huevo asesino, la bomba, sobre un atolón madrepórico del Pacífico. Los adelantos científicos usados sin valores humanistas y el problema ecológico son centrales en el cuento. 
En términos generales, cuando se habla de la realidad inmediata, lo sociocultural supera lo económico-político.

Como síntesis podría decirse que, a pesar de los nuevos intereses (las culturas minoritarias, lo ecológico, las nuevas tecnologías, lo político...), las viejas líneas temáticas siguen predominando. Lo propio, lo nuestro (en sentido personal y colectivo) se valora frente a lo extraño; lo cercano priva, sobre todo espacialmente, sobre lo alejado. El pasado sigue teniendo enorme relevancia, pero se modifica la perspectiva para enfrentarlo y la "actualidad" adquiere una relevancia pero se modifica la perspectiva para enfrentarlo y la "actualidad" adquiere una relevancia significativa. La naturaleza sigue considerándose un núcleo vital frente a los adelantos de la civilización.

\subsubsection{Los recursos en la escritura}

El aporte de otras prácticas significantes:

- la escritura se carga de una serie de recursos retóricos (técnicos) que provienen, sobre todo, de prácticas artísticas y comunicativas como el cine, la televisión, la pintura, la fotografía... Lo verbal, en algunos momentos, se vuelve imagen.

- los códigos se mezclan: la escritura verbal casi no se concibe sin la imagen que la acompaña, no ya simplemente como ilustración o apoyo, sino valorada como un trabajo en sí. Los nombres de los dibujantes aparecen en las portadas, el espacio dedicado a lo icónico aumenta, la calidad mejora notablemente.
Esta brecha también tiene historia: ¿Cómo no recordar los dibujos de Francisco Amighetti o Juan Manuel Sánchez? Hoy, los nombres de los artistas gráficos que trabajan en libros y revistas para niños y jóvenes se multiplican: Hugo Díaz, Cristina Fournier, Vicky Ramos, Georgina García, Félix Arburola...

- se introduce el estímulo a una participación más directa y concreta del niño. Hay tipos de literatura que de por sí empujan a la acción como es el teatro: una escritura hecha para ser representada, pero otras como la poesía o el cuento son menos evidentes.

Una práctica común -y a veces criticadaen la actualidad es la de dejar los dibujos en blanco y negro para colorear ( $L a \mathrm{voz}$ del caracol de Rodolfo Dada), incluir páginas en blanco (Cuentos de dos cielos y un sol de Mabel Morvillo) para dibujos o algunas líneas para que el niño escriba a su vez (Pantalones cortos de Lara Ríos).

- la inclusión de adivinanzas, chistes, refranes o dichos populares, juegos... provocan la repetición y la inclusion de ciertos elementos en el juego.

\subsubsection{En torno al proceso de circulación}

- Una tendencia clara en la actualidad es la relación, cada vez más estrecha, entre los medios de comunicación de masas y la literatura infantil. Esta colaboración se da de dos maneras:

- por una parte, se crean nuevos medios dedicados a los niños que incluyen la literatura infantil, hoy con un interés y perspectiva mucho más comercial: 
el ejemplo de Tambor (del Consorcio de La Nación) es significativo. Este tipo de revistas es diferente de las viejas revistas para niños, ni con la nueva versión de Triquitraque publicada, hasta hace algún tiempo, por el Instituto de Literatura Infantil y Juvenil.

- por otra parte, la literatura infantil se transforma en otros materiales significantes. Baste citar las historietas que elabora Hugo Díaz sobre algunos Cuentos de mi tía Panchita, los dibujos animados hechos a partir de Cocorí, las posibilidades que abren el cine, las series noveladas de televisión, los títeres, o el teatro televisado.

- El esfuerzo en el orden institucional se revela en los concursos dedicados a la literatura para niños y jóvenes que, necesariamente, estimulan la producción: Concurso Carmen Lyra (Editorial Costa Rica), Concurso UNA Palabra, Concurso de Literatura Infantil sobre temas relacionados con el medio ambiente (UNED). Incluso los premios nacionales, desde hace varios años, se otorgan a algunas obras narrativas, dramáticas o poéticas dedicadas a los niños. El premio Nacional de Teatro ganado por Leda Cavallini y Lupe Pérez y su texto Pinocho, es un buen ejemplo.

- Existe un esfuerzo - ¿tendencia?- a la organización con el Instituto de Literatura Infantil y Juvenil.

- Las editoriales impulsan la producción de literatura infantil no sólo a partir de concursos sino, además, incluyendo colecciones especializadas: Cumiche (EDUCA), Mapachín (EUNED).

La Editorial Costa Rica tradicionalmente brinda un apoyo significativo -tomando en cuenta sus condiciones-, las editoriales de las tres universidades estatales abren un espacio ( Universidad de Costa Rica, EUNED, EUNA), lo mismo que varias de las privadas: Porvenir, Nueva Década, Uruk.

\section{4. ¿Una literatura marcada por la edad del lector?}

La literatura para niños y jóvenes es literatura. Es también trabajo con el sentido, es productividad y es intertextualidad. Es un espacio programado y un espacio de transformación.

El problema más serio es el de los presupuestos, el de la "modelización", el de las programaciones sociales -conscientes e inconscientes- a las que se ajusta - ¿debe ajustarse?- el escritor, el crítico, el editor, el divulgador de los textos $\mathrm{y}$, por supuesto, el lector mismo.

Programaciones de escritura, programaciones temáticas, programaciones de lectura, programaciones de intercambio que pocas veces toman realmente en cuenta las posibilidades de transformación.

La literatura en general $-y$ para niños y jóvenes en particular- tiene un "deber ser" (determinados modelos y preceptivas que varían en el tiempo, el espacio, la clase social) y se le juzga según respete los ejes del programa o se aparte de ellos violentándolos.

- El problema estético (la belleza, el placer, el goce de los sentidos) se convierte, según este "debe ser", en un problema ético (moral, lo bueno y lo malo, lo falso y lo verdadero, lo positivo y lo negativo). 
- El juego con el significante se valora solo relativamente, porque el peso de lo didáctico parece seguir dominando lo lúdico. El niño puede jugar, sí, pero sobre todo debe aprender, adquirir conocimientos.

- La literatura "infantil" debe ser "formativa". Aun los que defienden a las brujas y los duendes lo hacen en favor "del desarrollo equilibrado del niño". La literatura como placer cede su lugar como "ingrediente de socialización", como posibilidad para crecer y madurar.

- El lenguaje deber ser "apropiado" para la edad (¿limitado, decente, culto?) y las temáticas -de acuerdo con la orientación hacia lo realista o lo fantástico que se sostenga- deben responder a las expectativas que los adultos creen que tienen los niños o, mejor aún, a las que "deben tener".

Este "debe ser o tener" de la literatura para niños y jóvenes limita las posibilidades del productor y condiciona la discusión sobre los textos particulares. La literatura puede ser $-\mathrm{y}$ tener- todos los rasgos que se le señalan como "ideales" dentro de una sociedad y en un tiempo determinados; el problema no son los espacios que se abren, sino las restricciones que limitan las posibilidades transformativas.

Los miedos a las acciones cotidianas negativas procuran evitarse y se privilegia -obsesivamente- un mundo donde no se trabaja, el mundo de la suerte y la casualidad, donde no existen la injusticia social, el crimen ni la violencia, las armas químicas biológicas y nucleares de los noticiarios televisivos o la página de sucesos o internacional de los periódicos.
Pero los niños participan de ese inframundo en que viven; ellos cuentan e inventan chistes políticos, sexuales o racistas y los entienden porque conocen de política, porque saben de tabúes sexuales y perciben el racismo o sufren las consecuencias del poder.

Los niños valoran la colaboración y la solidaridad, son capaces de entender la magia de una sonrisa y un rictus de dolor. Aman y destruyen la naturaleza, son oprimidos y oprimen, viven el detalle y captan la trascendencia, tienen miedo y manejan la ironía. Como "los grandes", quieren tomar el cielo con las manos y, a menudo, se caen de las escaleras de los sueños.

Construyen castillos, hablan con duendes, combaten gigantes y arrastran un automóvil de lata de sardinas, mientras cantan en inglés al ritmo de rock y repiten ensimismados frases, música, sonidos publicitarios que recuerdan marcas ansiadas.

Los estímulos del medio ambiente son múltiples, plurales, ambiguos, fragmentarios, disímiles... estimulan un sentido de pertenencia, de identidad y afirman la diferencia frente a otros.

Niños, jóvenes, adultos pertenecemos al pasado y fabulamos con él, vivimos e imaginamos el presente, soñamos y construimos el futuro. Y la literatura es ese espacio de productividad y transformación, de historia y de magia, de conservación y ruptura, por eso la literatura "para niños y jóvenes" es aquella que disfrutan los niños y los jóvenes, la que sienten y juegan, la que asumen, viven y transforman. 